\title{
RETOS DE LA IMPLEMENTACIÓN DE LOS SISTEMAS DE ARCHIVOS ${ }^{1}$
}

\section{Marcela Lorena Barraza Paredes ${ }^{2}$ Adria Velia González Beltrones ${ }^{3}$}

SUMARIO: Introducción II.Marco Teórico III. Control externo de la administración pública de Sonora IV. Control interno de la administración pública de Sonora V. Propuesta VI Corolario VII Bibliografía

\section{RESUMEN}

En el documento se analiza la nueva dimensión otorgada a los archivos[ a partir de diversas reformas constitucionales y disposiciones legales relacionadas con los sistemas locales y nacional en materia de anticorrupción, fiscalización, transparencia, acceso a la información,datos personales y de archivos] que responsabiliza, a los sujetos obligados, a transitar de un concepto de archivo operativo a la de un archivo integrado a las políticas democratizadoras, como insumo de la transparencia, acceso a la información, derecho a la verdad y memoria colectiva, lo que conlleva obligaciones jurídicas, administrativas y sociales de alto nivel,entre ellas, el minimizar los riesgos por discrecionalidad y abuso de poder en la destrucción y /o extracción de documentos durante el proceso de implementación de los subsistemas institucionales (SSIAr) y sistema general de archivos (SGAr) especialmente en las épocas de transición, por relevos sexenales, trianuales o personales [entrega-recepción]

PALABRAS CLAVE : Archivos, transparencia proactiva, entrega-recepción

\footnotetext{
${ }_{1}^{1}$ Ponencia presentada en el II Congreso de Archivos:Gestión Documental para la Transparencia y Rendición de Cuentas, Centro de Convenciones de las Artes de la Universidad de Sonora:Los archivos como insumo para la transparencia, rendición de cuentas y gobierno abierto. 19 y 20 de septiembre de 2019

2 Investigadora e Integrante de la Red Estatal de Archivistas,e-mail: marbarrazap@gmail.com

${ }^{3}$ Docente Investigadora del Departamento de Derecho, DCS, URC de la Universidad de Sonora, e-mail: adriag@sociales.uson.mx
} 


\section{Retos de la implementación de los Sistemas de Archivos}

Año 11, Número 21 julio-diciembre de 2019

Marcela Lorena Barraza Paredes y Adria Velia González Beltrones

\section{CHALLENGES OF THE IMPLEMENTATION OF FILE SYSTEMS ABSTRACT}

The document analyzes the new dimension granted to archives [based on various constitutional and legal reforms related to national and local systems in the area of anti-corruption, control, transparency, access to information, personal and archival data] hold the liable parties accountable, to move from a concept of operational file to that of an integrated file to democratizing policies, as an input of transparency, access to information, right to truth and collective memory, which entails legal obligations, high-level administrative and social, including minimizing risks due to discretion and abuse of power in the destruction and / or extraction of documents during the process of implementing institutional subsystems (SSIAr) and general file system (SGAr) especially in times of transition, for six-year, three-year or personal relays [ delivery reception]

KEYWORDS: Archives, proactive transparency, delivery-reception

\section{INTRODUCCIÓN}

Nuestro país, desde la ley de transparencia anterior (2002) impelido por transparencia internacional, en el camino para combatir a la corrupción, ha transitado, con pasos demasiado pausados, en su propósito de incorporar al sistema nacional y global de valores, la transparencia, el acceso a la información, la rendición de cuentas y el combate a la corrupción es decir, tales actividades se han sucesivamente armonizado y sistematizado en los respectivos sistemas nacionales, como parte de una reforma constitucional $y$, paradójicamente, la actividad que implica (archivos) el soporte de todas ellas, se ha mantenido desvinculada, no obstante llegar recientemente a la expedición de la ley general de archivos (2018) conforme a la cual, tanto los gobiernos federal,locales y municipales 
deberán armonizar sus leyes a fin de preservar, organizar, registrar,administrar y conservar la documentación en posesión de los sujetos obligados ${ }^{4}$.

Las políticas públicas de transparencia, rendición de cuentas $^{5}$ y acceso a la información, en México, han generado redimensionamiento en el quehacer de la administración pública con los mecanismos institucionales que fortalecen la rendición de cuentas, como lo son, el sistema nacional de transparencia, acceso a la información y protección de datos personales, sistema nacional anticorrupción,el sistema nacional de fiscalización y el sistema nacional de archivos (SNAr) es en este último,-en el que centraremos nuestra atención, mencionando que con la reciente publicación de la Ley General de Archivos (15 de junio de 2019) se obliga a las entidades federativas y a sus municipios e igualmente al ámbito de gobierno federal; a la armonización de las leyes de la materia, en sus respectivas demarcaciones territoriales y/o por competencia .

Si bien dicha armonización pretende la homologación de la organización de los archivos en el orden local y federal, lo más relevante es el redimensionamiento de la función; puesto que más allá de reflejar y de evidenciar el quehacer administrativo de la administración pública, dicha función se extiende a contribuir

\footnotetext{
${ }^{4}$ Artículo 10. Cada Sujeto Obligado es responsable de: organizar y conservar sus archivos; de la operación de su sistema institucional;del cumplimiento de lo dispuesto por esta ley; las correspondientes de las entidades federativas y las determinaciones que emita el Consejo Nacional o el Consejo Local, según corresponda; y deberán garantizar que no se sustraigan, dañen o eliminen documentos de archivo y la información a su cargo.

5 Rendición de cuentas es la obligación que tienen los representantes del poder, tanto políticos como funcionarios, de mantener a disposición la información que generan, que esta última es de carácter público, la sociedad tiene el derecho de conocer las actuaciones comprobación de sus actos y decisiones realizadas en función de sus obligaciones.Ambos aspectos, justificación de los actos y decisiones, se constituyen en registros documentales que revelan la naturaleza de su propia creación. En otras palabras la Rendición de Cuentas debe estar soportada en la documentación relacionada con la actuación de que se trate y resguardada en un archivo físico y/o electrónico .
} 


\section{Retos de la implementación de los Sistemas de Archivos}

Año 11, Número 21 julio-diciembre de 2019

Marcela Lorena Barraza Paredes y Adria Velia González Beltrones

al ejercicio del derecho a la verdad y a la memoria, de conformidad con las disposiciones aplicables.

\section{DIAGNÓSTICO}

En el caso de Sonora los retos son grandes, porque actualmente la organización de archivos ha estado bajo la disposición de cada uno de los sujetos obligados sin técnicas y lineamientos administrativos uniformes, a pesar de existir algunas referencias normativas; además, que se carece en la estructura gubernamental de una figura coordinadora de los archivos del estado, por lo que no se conoce de manera integral cuál es el estatus que guardan los archivos de cada dependencia y/o entidad estatal del poder ejecutivo, poder legislativo,poder jurisdiccional, órganos autónomos y municipios; además de aquellos qu sean de interés público sin ser parte de la administración pública.

\section{A MANERA DE HIPÓTESIS}

La implementación de los subsistemas de archivos institucionales SSIAr, es solo una parte de lo que exige la ley, ya que en sí, se requiere crear todo el sistema de archivos del estado SEAr lo que implica coordinar a todos los sujetos obligados conforme a la normatividad aplicable. A su vez, los sistemas de archivos locales y del ámbito federal son parte de un macro sistema (conformado por los sistemas locales y federal (anticorrupción, fiscalización, transparencia y acceso a la información y de archivos) vease Figura 1. 


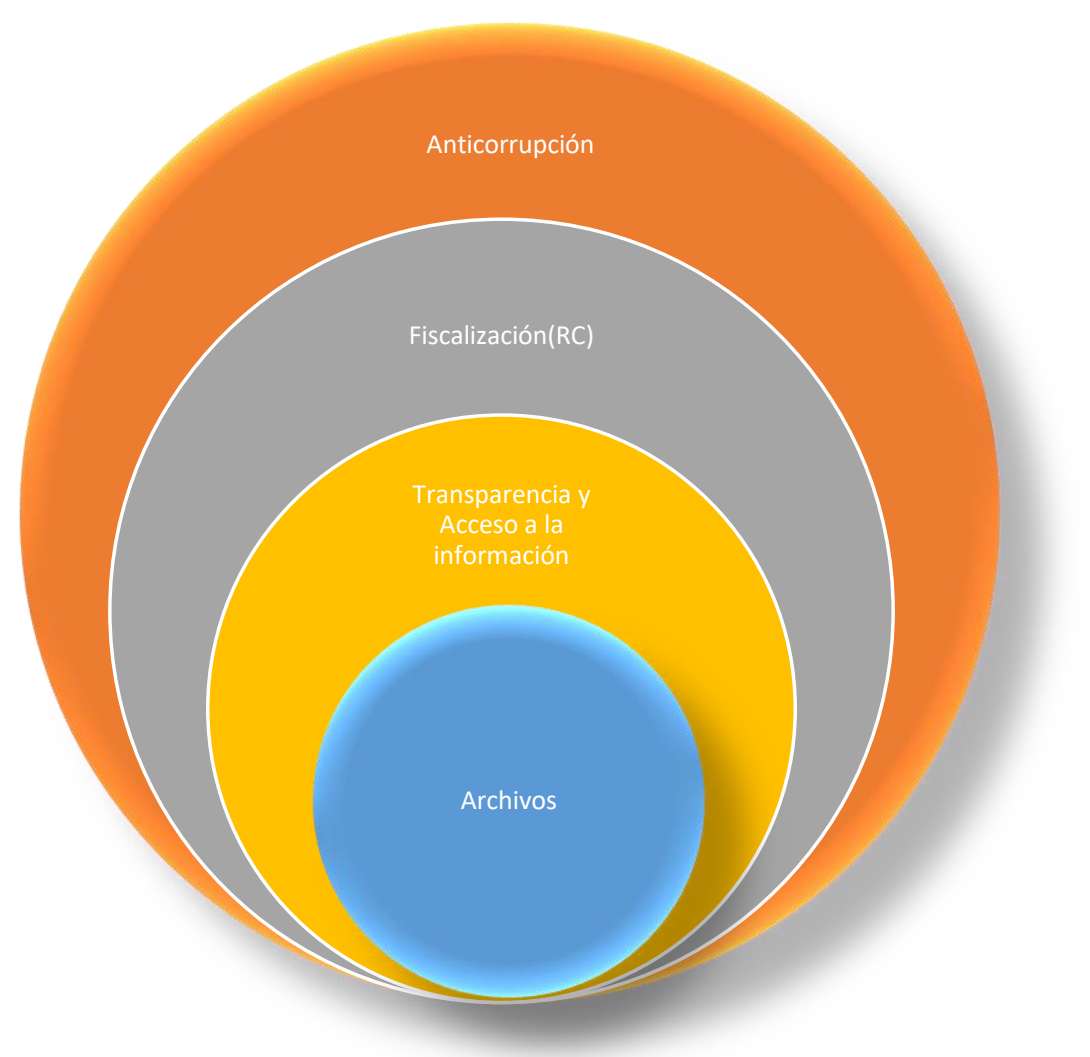

Figura . 1. Ubicación de los archivos como parte de un macro sistema

En este sentido, tratandose de la implementación del sistema de archivos del estado de sonora,SEAr, en la Tabla 1, lineas debajo, se muestra de manera diagnóstica las etapas que al efecto,se considera necesario desarrollar, la ruta crítica a seguir y las actividades coordinadas con los sujetos obligados acorde a la normatividad aplicable.

Es decir, que al publicarse la Ley de Archivos de Estado de Sonora, armonizada, El sistema Estatal de Archivos deberá integrarse inmediatamente con el fin de que cumpla con las disposiciones correspondientes, en coordinación con los sujetos obligados para que estos estructuren o adecuen sus Subsistemas 


\section{Retos de la implementación de los Sistemas de Archivos}

Año 11, Número 21 julio-diciembre de 2019

Marcela Lorena Barraza Paredes y Adria Velia González Beltrones

institucionales de archivo SSIAr. Estos Subsistemas desde luego que no pueden estar listos de la noche a la mañana, porque requieren de diseño para implementar las nuevas estructuras, infraestructura, recursos humanos con competencias y desde luego financieros, para cumplir con los requerimientos exigidos en la Ley, por lo que deberán presentar proyecciones a corto, mediano y largo plazo. Además, en caso del Estado de Sonora, no se cuenta en la estructura gubernamental con un Archivo General AGESON (Art. 17 de LGA) Por lo que, se deberá prever su creación como la entidad especializada en materia de archivos. Su titular deberá tener nivel de Secretarío, titular de unidad administrativa o su equivalente, debiendo recordar que es requisito que el titular del Archivo General de Estado sea quien presida el Consejo del Sistema Estatal CSEAr. A la fecha en ninguno de los tradicionales tres poderes ni en los Organos autónomos, se cuenta con Archivos organizados con técnicas archivisticas uniformes (en el poder judicial solo se cuenta con uno en materia sustantiva, pero no incluye la administrativa.)

En el mismo tenor, recordar que al SEAr es a quien corresponderá, según el art. 71 de LGA de Implementar las políticas, programas, lineamientos y directrices para la organización y administración de los archivos que establezca el Consejo Nacional; así como Aprobar criterios para homologar la organización y conservación de los archivos locales; entre otras atribuciones

Para poder llevar a cabo su función de una manera planificada, es importante que se parta de un diagnóstico de las condiciones en que se encuentra todos los archivos de las entidades y dependencias en los tres poderes, los municipios y los órganos autónomos; desde luego con fines de conocer el patrimonio documental, deben incluirse los archivos privados de interés público.Si bien el SEAr debe impulsar la homologación de los archivos, es necesario que se coordine con las dependencias y entidades tanto las de control como las propias que llevaran a cabo la integración institucional de sus sistemas de archivo. 
Tabla 1: Implementación del sistema estatal de archivos SEAr

\section{Implementacion del SEAr}

Sistema

Contar con una ley estatal de archivos

Contar con el archivo
general
AGESON

\section{Establecer el SEAr}

Determinar
representatividad de
los municipios dentro
del SEAr

$Y$ redactar los lineamientos $y$ manuales para los

Subistemas institucionaes de archivosSSEAr

\section{Ruta crítica}

Proyección del sistema estatal de archivos a corto, mediano y largo plazo

\section{Elaboración de un diagnóstico estatal de los archivos institucionales}

\section{Presupuestar la} implementación del sistema

\section{Determinar los} requerimientos para la implementación y seguimiento de la implementación del sistema

Coordinación con las contraloría y coordinaciones de archivo de los sujetos obligados
Coordinación con lo sujetos obligados

Presentación de la estructura y logística de la implementación de los sistemas institucionales de archivo SSIAr

Capacitaciones administrativas, jurídicas y técnicas de archivo para la implementación de sus SSIAr
Elaboración de proyectos de implementación de SubSistemas institucionales de archivosSSIAr

Gestión de estructura y recursos para la implementación del sistema institucional de archivos

Seguimiento y verificación de sus avances y cumplimiento de indicadores

\section{MARCO TEÓRICO}

Haciendo un paréntesis, para sustentar teóricamente el tema de nuestra participación, requiere encuadrar a los archivos organizados con base en la gestión 


\section{Retos de la implementación de los Sistemas de Archivos}

Año 11, Número 21 julio-diciembre de 2019

Marcela Lorena Barraza Paredes y Adria Velia González Beltrones

documental, como insumo fundamental para coadyuvar en la ardua tarea de combatir la corrupción.

Para nadie pasa desapercibido que entre los actos más importantes de todo gobierno lo es el de la hacienda pública, de ahí la importancia de garantizar a los contribuyentes, que aportan una porción de sus riquezas para el sostenimiento del estado, la seguridad de que sus contribuciones son destinadas a los rubros autorizados legalmente en los presupuestos (municipal, estatal o local y federal. Por lo que en la medida que los ciudadanos ejerzan su derecho de acceso a la información, se percatarán del poder que tienen de fiscalizar y de exigir a los gobiernos, les rindan cuentas de su actuación, funciones, atribuciones y primordialmente del destino de los recursos obtenidos de "sus bolsillos" como lo son los tributos.

Al efecto los Doctores Fernández Ruiz y Aragón Salcido ${ }^{6}$, subrayan atinadamente que

"...la historia apunta con terquedad que uno de los peligros permanentes en todo estado es la posible corrupción de sus agentes; el propósito de prevenirla y evitarla demanda el ejercicio de la función pública de fiscalización o control, mediante el desempeño de una actividad técnica y esencial del ente estatal dirigida a vigilar, verificar, comprobar y evaluar las actividades de los órganos, dependencias y servidores públicos a cuyo cargo está el manejo de los fondos, valores, recursos, bienes y derechos del propio estado."

En este tenor, no queda a discusión ---por lo inherente a la naturaleza intrínseca de la actividad denominada administración --- que toda organización política o social, pública o privada, debe contar con órganos de control y vigilancia

\footnotetext{
${ }^{6}$ Férnandez Ruiz J,Aragón Salcido M. I., Derecho Administrativo de Sonora,México,Ed.Porrúa, 2014 pp.429
} 
que hagan factible detectar las desviaciones de su actuación respecto de las disposiciones jurídicas que regulan su desempeño y, en consecuencia, poder corregir tales desvíos, a efecto de alcanzar los fines, objetivos y metas previstos.

En el caso del control y vigilancia de la administración pública se puede dar desde dentro de la propia administración (control interno) y desde fuera (control externo); en el segundo caso, por medio de los órganos jurisdiccionales, del órgano legislativo, del órgano de fiscalización superior, que en el ámbito federal de nuestro país es la auditoría superior de la federación, y del ombudsman.

Desde dentro, nuestra administración pública federal ejerce la función de fiscalización a través de la Secretaría de la Función Pública, de la Secretaría de Hacienda y Crédito Público, de las contralorías internas de cada una de sus dependencias y entidades, así como por medio del recurso administrativo. Lo anterior, con sus debidas especificidades, se presenta también en la administración pública de la indebidamente denominada Ciudad de México (antes Distrito Federal) y en las de los estados y en las de sus municipios. ${ }^{7}$

En palabras de José Trinidad Lanz Cárdenas, "en el campo de la función pública, por control debe entenderse el acto contable o técnico que realiza un poder, un órgano o un funcionario que tiene atribuida por la ley, la función de examinar la conveniencia o la legalidad de un acto o una serie de actos y la obligación de pronunciarse sobre ellos". 8

${ }^{7}$ González Beltrones Adria Velia, Vease Control y Vigilancia de la Administración Pública Municipal, en BIOLEX Revista Jurídica del Departamento deDerecho,DCS UNISON URC Academia de Derecho Administrativo Tercera Época Año 7. Núm. Edición Especial Julio-Diciembre de 2015, pp.5,Colección de Estudios Municipales Tomo III "Control y Vigilancia de la Administración Pública Municipal" 8 Lanz Cárdenas, José Trinidad, La contraloría y el control interno en México, México, FCE, 1987, pp. 32. 


\section{Retos de la implementación de los Sistemas de Archivos}

Año 11, Número 21 julio-diciembre de 2019

Marcela Lorena Barraza Paredes y Adria Velia González Beltrones

\section{CONTROL EXTERNO DE LA ADMINISTRACIÓN PÚBLICA DE SONORA}

Para mantener el orden constitucional se requiere el control de los órganos depositarios de las funciones del poder público lo que tiene como objetivo la acotación del poder y el aseguramiento de la racionalidad de su ejercicio, que a su vez implica, además de realizar su control interno, la sujeción de la administración pública (al igual que los otros dos poderes y los órganos autónomos) a un régimen de control externo.

Es observable, la existencia de dos sujetos en el control externo: el sujeto activo o controlador y el sujeto pasivo o controlado. En el orden jurídico mexicano, son sujetos activos del control externo respecto del poder ejecutivo, los órganos jurisdiccionales, el órgano legislativo, el órgano de fiscalización superior y el ombudsman; respecto del poder jurisdiccional, el órgano ejecutivo, el órgano legislativo por medio del órgano de fiscalización superior y el ombudsman; respecto del poder legislativo :los órganos jurisdiccionales y el ombudsman y el que debiera ser control externo, dado que a la Auditoria Superior de la Federación en las Reformas de 2017, no se le concedió expresamente la autonomía, por lo que respecto del poder legislativo, viene a ser "control interno," de allí la frase ¿"quién vigila al vigilante"?

En razón del tema que nos ocupa, nos detendremos brevemente en el

\section{CONTROL INTERNO DE LA ADMINISTRACIÓN PÚBLICA}

Dado que, resulta de importancia vital, que las autoridades cumplan con documentar, registrar y conservar debidamente las actuaciones realizadas en ejercicio de las facultades que les confieren los diversos ordenamientos y disposiciones jurídicas a efecto de deslindar responsabilidades. En esta exposición de ideas, cabe recordar que en México en el orden federal, local y municipal se establece el control interno mediante diversas acciones desarrolladas por diferentes dependencias y órganos del sector paraestatal durante el ejercicio fiscal 
que corresponda. Lo anterior, principalmente, a través de la Secretaría o sus homólogas a quienes se les atribuya jurídicamente realizar, entre otras, dicha función, que en el caso de nuestro Estado de Sonora lo es la Secretaría de la Contraloría General ${ }^{9} \mathrm{y}$ los enlaces en las dependencias, los órganos de control de cada una de las entidades del sector paraestatal y los homólogos de los órganos autónomos). Asimismo, a partir de las Reformas Constitucionales del 2014 y la entrada en vigor del Sistema Nacional Anticorrupción asumen, absurdamente, parte del control interno (sancionar las infracciones graves) los Tribunales Contenciosos Administrativos de las entidades federativas y el Tribunal De Justicia Administrativa Federal por medio de las salas especializadas en materia anticorrupción. Otra de las dependencias del poder ejecutivo estatal, encargada del control interno, lo es, la

\section{SECRETARÍA DE HACIENDA}

Que en el caso del estado de Sonora, por disposición de la ley dicha Secretaría tiene a su cargo el despacho de los asuntos que expresamente le confieren la ley orgánica del poder ejecutivo del Estado de Sonora en su artículo 24, y otras leyes, así como los reglamentos, decretos, acuerdos, circulares y órdenes del gobernador del estado, destacando principalmente la de recaudar los tributos así como administrar los ingresos financieros. Otra forma de control interno lo encontramos en la regulación del

\section{RECURSO ADMINISTRATIVO}

Cuyo establecimiento en nuestra legislación, permite que los errores y excesos de la administración pública, en perjuicio de los particulares, sean

\footnotetext{
${ }^{9}$ La Secretaría de la Contraloría General, fiscaliza y controla a las dependencias y entidades de la administración pública del Estado de Sonora, en ejercicio de facultades expresas que le confieren la Ley Orgánica del Poder Ejecutivo del Estado de Sonora en su artículo 26, la Ley del Presupuesto de Egresos, Contabilidad Gubernamental y Gasto Público Estatal, otros ordenamientos legales y reglamentarios y el Decreto que aprueba el Presupuesto Anual de Egresos del Estado de Sonora.
} 


\section{Retos de la implementación de los Sistemas de Archivos}

Año 11, Número 21 julio-diciembre de 2019

Marcela Lorena Barraza Paredes y Adria Velia González Beltrones

corregidos por ella misma, sin la intervención de otros órganos del poder público, por lo que se le considera un mecanismo de autocontrol; que como bien apunta el doctor Gonzalo Amienta Hernández, "más que una prerrogativa de la autoridad para corregir sus errores es un medio de defensa del administrado" ${ }^{10}$.en los artículos 106 y 107, la Ley de Procedimiento Administrativo del Estado de Sonora, establece que : "contra los actos y resoluciones definitivas que expidan las autoridades administrativas, el interesado podrá, a su elección,interponer el recurso de inconformidad previsto en esta Ley o intentar el juicio correspondiente ante el Tribunal de lo Contencioso Administrativo del Estado de Sonora...dentro de los quince días hábiles siguientes al en que surta sus efectos la notificación de la resolución o acto que se recurra, o de que el recurrente tenga conocimiento de dicha resolución.

Cabe mencionar que, esta ley (Artículo $1^{\circ}$ ) no es aplicable en las materias de seguridad pública y tránsito, responsabilidades de los servidores públicos, participación ciudadana, acceso a la información y al ministerio público en ejercicio de sus funciones constitucionales. En materia tributaria, solamente será aplicable al procedimiento administrativo de ejecución, por lo que quedan subsistentes los recursos administrativos previstos en las leyes aplicables a dichas materias.

En este tenor, dentro de los mecanismos de control interno, cabe referirnos al de

\section{ENTREGA-RECEPCIÓN DE LA ADMINISTRACIÓN PÚBLICA.}

Considerado por los expertos como un control preventivo, dentro de un ejercicio de rendición de cuentas, el cual en palabras de Guillermo Haro Bélchez, se caracteriza por ser "... un acto jurídico administrativo por el cual se transfieren a la nueva autoridad, las responsabilidades, competencias, recursos y componentes organizativos, técnicos y procesos operativos, con los que se desempeña la

\footnotetext{
${ }_{10}$ Armienta Hernández, Gonzalo, Tratado teórico práctico de los recursos administrativos, México, Porrúa, 1991.
} 
administración pública estatal". ${ }^{11}$..."De esta manera, la entrega y recepción constituye un verdadero esquema de inducción y apoyo para las próximas autoridades estatales". ${ }^{12}$

Así, en todo proceso de Entrega-recepción, deberán tomarse medidas emergentes que minimicen el riesgo de posible pérdida de los documentos en la transición, por toma de decisiones discrecionales, en los momentos clave que se dan en los cambios de administración y/o en caso de separación temporal o definitiva del cargo de los servidores públicos responsables.

En este contexto, cabe referirnos a los tipos de riesgos que pueden surgir en el inter de que se implemente el sistema SEAr de nuestro Estado de Sonora y los de sus homólogos en toda la República, asimismo, señalar algunas estrategias para iniciar organizadamente la preservación de los archivos actuales, la producción de nueva información y documentos, su registro y conservación de conformidad con la futura Ley de Archivo Estatal, ${ }^{13}$ que deberá ser armonizada a lo dispuesto en la Ley General de Archivos.(Vease Tabla 2)

\footnotetext{
${ }_{11}$ Haro Belchez, Guillermo, Coordinador, Avances y Retos del Sistema de Control y Evaluación de la Gestión Pública y Desarrollo Administrativo en el estado de México 1993-1999, Instituto Nacional de Administración Pública, Toluca, Estado de México1999, pp. 497

12 Ibídem, pp. 498

${ }^{13}$ El 15 de junio de 2018, se publicó en el Diario Oficial de la Federación la Ley General de Archivos, la cual,precisa en sus disposiciones transitorias que la misma entrará en vigor a los 365 días siguientes contados a partir de su publicación en el Diario Oficial de la Federación, es decir, entró en vigor el 16 de junio de 2019, y señala en el artículo cuarto transitorio que las legislaturas locales tendrán un año a partir de la entrada en vigor de la Ley General, para armonizar sus leyes de archivo, es decir, tienen como fecha límite hasta el 16 de junio de 2020, para tener aprobada y publicada en el Boletín o Gaceta Oficial del Gobierno Local de que se trate, las Leyes de Archivos Locales armonizadas con lo que dispone la Ley General de Archivos.
} 


\section{Retos de la implementación de los Sistemas de Archivos}

Año 11, Número 21 julio-diciembre de 2019

Marcela Lorena Barraza Paredes y Adria Velia González Beltrones

La ley General de Archivos que establece y faculta al Sistema Nacional de Archivos para que por medio de Sistemas locales de Archivo se logre de manera coordinada la implementación de un sistema homólogo para la organización y preservación de los archivos, quedando los sistemas locales como los responsables de que en cada entidad federativa se lleven a cabo las acciones necesarias para ello. Esta homologación se requiere, principalmente, porque ante un proceso que debiera ser protegido y vigilado, es en realidad uno de los menos cuidados en todo sentido en la asignación de recursos, en no tomar la administración de los archivos como función sino como tarea, olvidando que son parte de los bienes muebles del estado y el generador del patrimonio nacional.

En la normatividad actual, relacionada con la entrega recepción de las administraciones y de los sujetos obligados que dejan su cargo, no se contempla la entrega ---de lo que, de aprobarse la iniciativa de Ley de Archivos para el Estado de Sonora- se denominará SubSistema Institucional de Archivos SSIAr. La actual Ley de Entrega Recepción para el Estado de Sonora, solo se refiere, en términos generales, en sus artículos 1,4,5,7,9,15,17 y 21, a la obligación "de entregar a quienes los sustituyan al término de su empleo, cargo o comisión, los recursos humanos, materiales, financieros y tecnológicos, así como documentos y demás información generada en el ejercicio de sus funciones" sin mencionar la palabra archivos. Y en el Reglamento de la Ley de Entrega Recepción del Estado de Sonora (2015) como única mención que se hace respecto a los archivos es lo dispuesto :

Artículo 21. Fracc. II Sistema de Evidencias (SEVI): herramienta informática donde se integra evidencia generada por la realización de obras públicas, adquisiciones y otros programas de gobierno.

Artículo 25. La información que para la entrega- recepción referente a la integración de expedientes Únicos deberán presentar los sujetos obligados que tengan a su cargo la 
realización de obras públicas o ejecución de programas de gobierno, se emitirán mediante el SEVI*

Artículo 26. Los expedientes únicos a que se refiere el artículo anterior permanecerán en los archivos destinados para su resguardo en las Dependencias y Entidades ejecutoras de obra pública y programas de gobierno, los cuales estarán sujetos a las revisiones del personal de la contraloría.

Lo anterior es toda la indicación respecto a cómo hacer la entrega - recepción del archivo, refiriéndose prácticamente a un inventario de expedientes, que es lo que se registra en el SEVI en la plantilla de expedientes (no queda claro si en paralelo al SEVI se lleva el inventario físico de los documentos que deberian integrar los "expedientes unicos".

De la misma parte,cuando se realiza el proceso de entrega - recepción no se lleva a cabo una constatación de los inventarios más allá de los expedientes de interés y, en muchas ocasiones, cuando algo se reclama de manera directa o a través de transparencia, se "justifica el no proporcionarlos", con mencionar que ....."la anterior administración no dejó evidencias". Esto es el resultado de la falta de Subsistemas de Archivo Institucionales SSIAr coordinados en una única línea que elabore homogéneo el proceso. Lo que debe ser premisa es que partir de la nueva normatividad en archivos, se considere prioridad y se establezca la obligación de la entrega - recepción no solo de archivos, sino de todo el Subsistema Institucional de Archivo de la Dependencia o Entidad que corresponda, con base en una disposiciòn jurídica explícita.

Pero mientras esto sucede, el riesgo de la desaparición de los documentos sigue vigente, tanto aquellas evidencias de soporte físico como las electrónicas. Estas últimas ni siquiera se consideran parte del archivo, ya que toda su administración y decisión de seguridad y conservación está en manos de las áreas de sistemas informáticos con disposición directa de la alta Dirección quedando fuera de todo control documental sin ser reconocido, hasta el momento, como patrimonio documental. 


\section{Retos de la implementación de los Sistemas de Archivos}

Año 11, Número 21 julio-diciembre de 2019

Marcela Lorena Barraza Paredes y Adria Velia González Beltrones

Grave problema representa esto para proteger los archivos, en el lapso que queda entre la instalación del SEAr y la implementación de los Subsistemas institucionales de archivo SSIAr; así como el que los sujetos obligados que operan el control, vigilancia y fiscalización cuenten con los procedimientos y recursos adecuados para ejercer su función acorde a lo dispuesto por la Ley General de Archivos o en su momento por la Ley de Archivos del Estado de Sonora.

Por ello se recomienda que se genere normatividad preventiva, necesaria para minimizar al máximo este problema en los cambios administrativos y relevo de funcionarios, en cualquier nivel jerárquico y en los tres poderes del estado órganos autónomos y municipios.

Los documentos que se generan por los sujetos obligados, deben ser producidos de manera racionalizada, que tengan una congruencia entre el peso del tipo de documentos con la información contenida, de igual manera la legitimidad de la firma; cada tipo de documento tiene una función, sin embargo en la administración pública esto no se tiene contemplado dentro de las políticas de la producción y reproducción de documentos, restándole valor a los documentos. Además, de que la reproducción en papel o digital genera la explosión documental; esto sucede porque los procedimientos no están ligados a la generación de expedientes, provocando confusión en la conformación y la valoración documental.

El desconocimiento de la disciplina archivística y las leyes que aplican al respecto (directa e indirectamente) por parte de los servidores públicos, generan el riesgo de la decisión errónea en la selección de documentos de conservación permanente, según se esquematiza en la siguiente Tabla 2 "Cuatro momentos de la gestión documental que pueden representar un riesgo". 
Tabla 2 Cuatro momentos de la gestión documental que pueden representar un riesgo.

\begin{tabular}{|l|l|l|l|}
\hline $\begin{array}{l}\text { Existencia de los } \\
\text { documentos }\end{array}$ & Registros & Conservación & $\begin{array}{l}\text { Reacción } \\
\text { cambio }\end{array}$ \\
\hline $\begin{array}{l}\text { Elaboración } \\
\text { adecuada y } \\
\text { completa que } \\
\text { evidencien los } \\
\text { trámites y toma } \\
\text { de decisiones } \\
\text { de los sujetos } \\
\text { oficiales }\end{array}$ & $\begin{array}{l}\text { De los } \\
\text { documentos de } \\
\text { toda } \\
\text { información } \\
\text { generada, } \\
\text { recibida y } \\
\text { transformada } \\
\text { en el marco de } \\
\text { sus funciones }\end{array}$ & $\begin{array}{l}\text { Valoración con } \\
\text { criterios técnicos } \\
\text { actualizados } \\
\text { conforme a las } \\
\text { exigencias de la ley, } \\
\text { que incluye el } \\
\text { derecho a la verdad, } \\
\text { ylo que implica los } \\
\text { aspectos de la } \\
\text { memoria y fines de } \\
\text { investigación }\end{array}$ & $\begin{array}{l}\text { Sensibilizar e } \\
\text { informar de las } \\
\text { implicaciones de } \\
\text { la implementación } \\
\text { del sistema } \\
\text { institucional de } \\
\text { archivos a todos } \\
\text { los niveles }\end{array}$ \\
\hline $\begin{array}{l}\text { Manuales de } \\
\text { procesos } \\
\text { procedimientos } \\
\text { reales, } \\
\text { completos } \\
\text { actualizados }\end{array}$ & $\begin{array}{l}\text { Soporte físico y y } \\
\text { electrónico }\end{array}$ & $\begin{array}{l}\text { Eliminar } \\
\text { discrecionalidad y y } \\
\text { abuso de poder en la } \\
\text { destrucción y } \\
\text { Extracción de } \\
\text { Documentos en los } \\
\text { procesos de entrega } \\
\text { recepción }\end{array}$ & $\begin{array}{l}\text { Sensibilizar e } \\
\text { informar de las } \\
\text { sanciones en } \\
\text { caso de incumplir } \\
\text { con la } \\
\text { normatividad para } \\
\text { la implementación } \\
\text { del sistema } \\
\text { institucional de } \\
\text { archivos a todos } \\
\text { los niveles }\end{array}$ \\
\hline
\end{tabular}

A partir de la entrada en vigor de la Ley General de Archivos [15-06-2019] cuya finalidad es, establecer los principios y bases para la organización y conservación, administración y preservación homogénea de los archivos a nivel nacional en posesión de cualquier ente que maneje recursos públicos, las entidades federativas cuentan con un año de plazo para armonizar sus ordenamientos relacionados con la precitada Ley General de Archivos. Por ello es fundamental actualizar y profesionalizar la labor de quienes tienen bajo su resguardo el acervo archivístico, manejo de documentos e información de carácter público o privado,a fin de garantizar el resguardo y protección de bienes documentales, así como el 


\section{Retos de la implementación de los Sistemas de Archivos}

Año 11, Número 21 julio-diciembre de 2019

Marcela Lorena Barraza Paredes y Adria Velia González Beltrones

realizar la gestión eficiente de los archivos para facilitar y garantizar con ello el acceso de la ciudadanía a la información pública. Pues cabe recordar que el correcto manejo, custodia y mantenimiento de la información en los archivos es un elemento adicional a lo dispuesto por la Ley General de Contabilidad Gubernamental, que establece requisitos en cuanto a la custodia y el manejo de la documentación comprobatoria del gasto público, lo que facilita realizar procesos de fiscalización debidamente sustentados.

Si bien el papel asignado a los archivos, no es propiamente combatir la corrupción, sino mas bien, evidenciar su existencia o inexistencia; ello resalta la importancia de realizar acciones conjuntas de los gobiernos (federal,local y/o municipal) y la sociedad, para realmente hacer frente común al logro de tal objetivo. En este sentido,además de participar en la decisión del destino de los recursos públicos(presupuestos participativos)su ejercicio y evaluación, a posteriori, debe ser vigilado y realizado respectivamente por la propia ciudadanía.

Lamentablemente el tema de la corrupción en el mundo entero, ha venido avanzando. De allí que los archivos y la gestión documental, el pleno ejercicio transparente de los recursos públicos y la rendición de cuentas deben ser siempre la divisa con la que se desempeñen nuestras instituciones,no únicamente porque generan confianza social y coadyuvan al combate a la corrupción, sino porque también contribuyen a fortalecer el sistema democrático y el estado de derecho mexicano.A continuación un resumen de propuestas (Vease Tabla3) que incluye el hacer transparente la implementación del SEAr y de los SubSistemas Institucionales de Archivo (Ya que conlleva, entre otros rubros, el presupuestal que será de gran monto) cumpliendo así con la transparencia proactiva ${ }^{14}$. Seguridad de los documentos existentes y complementar las leyes relacionadas.

\footnotetext{
${ }^{14}$ La transparencia proactiva se establece en el artículo 3 Fracción XXI de la Ley de Transparencia y Acceso a la Información del Estado de Sonora, al señalar que son:
} 
Tabla 3. Esquema de Propuestas

\begin{tabular}{|c|c|c|}
\hline $\begin{array}{l}\text { Cumplir con la } \\
\text { transparencia } \\
\text { proactiva }\end{array}$ & $\begin{array}{l}\text { Proteger } \\
\text { documentos } \\
\text { existentes }\end{array}$ & $\begin{array}{l}\text { Complementar las } \\
\text { leyes relacionadas }\end{array}$ \\
\hline $\begin{array}{l}\text { Publicitando desde el } \\
\text { portal de transparencia } \\
\text { SEAr, en coordinación } \\
\text { con los responsables de } \\
\text { los archivos de cada } \\
\text { sujeto obligado. }\end{array}$ & $\begin{array}{l}\text { No permitiendo la } \\
\text { aplicación de los } \\
\text { actuales CaDiDos* o la } \\
\text { destrucción por destino } \\
\text { final de los documentos, } \\
\text { en el período de } \\
\text { transición de la } \\
\text { publicación } \\
\text { lineamientos de } \\
\text { manuales } \\
\text { correspondientes. }\end{array}$ & $\begin{array}{l}\text { Complementar } \\
\text { actualizar la ley de } \\
\text { entrega-recepción con } \\
\text { lineamientos y } \\
\text { reglamentos especiales } \\
\text { para los archivos } \\
\text { institucionales. }\end{array}$ \\
\hline $\begin{array}{l}\text { Transparentar la gestión y } \\
\text { ejecución de proyectos, } \\
\text { los avances técnicos y } \\
\text { administrativos de cada } \\
\text { sujeto obligado respecto } \\
\text { a su estado inicial y } \\
\text { cronograma. }\end{array}$ & $\begin{array}{l}\text { Sistematizar la } \\
\text { administración de la } \\
\text { información electrónica } \\
\text { y los documentos } \\
\text { electrónicos con la } \\
\text { finalidad de protegerlos } \\
\text { en el proceso. }\end{array}$ & $\begin{array}{l}\text { Protección de la } \\
\text { inversión en el capital } \\
\text { humano, Tecnologías, } \\
\text { infraestructura y equipo. }\end{array}$ \\
\hline
\end{tabular}

Obligaciones de transparencia: La información que los sujetos obligados deben difundir, actualizar y poner a disposición del público en medios electrónicos de manera proactiva, sin que medie solicitud de por medio;

- CaDiDos: Catálogo de disposición documental, aplicable lo dispuesto por el Archivo General de la Nación en su Instructivo para la elaboración del Catálogo de disposición documental, cuya finalidad es registrar en forma sistemática los resultados del proceso de identificación y valoración de las series documentales durante su "ciclo vital".

Fecha de actualización: 16 de abril 2012 [en línea] Disponible en:

http://www.agn.gob.mx/menuprincipal/archivistica/pdf/instructivoCADIDO 20072012.pdf, consultado el 23 de agosto de 2019, 


\section{Retos de la implementación de los Sistemas de Archivos}

Año 11, Número 21 julio-diciembre de 2019

Marcela Lorena Barraza Paredes y Adria Velia González Beltrones

\section{Corolario}

La gestión documental y los archivos son necesarios para coadyuvar en la ardua tarea de combatir la corrupción, úlcera que impacta y afecta gravemente, el desarrollo económico de los países que, como México, han emprendido una serie de medidas normativas y organizacionales ( reformas a nuestra carta magna, legislación de orden, federal, local y municipal,creación y/ o modificación de instituciones) tendientes a abatir el grave problema, para lo cual, es necesario la participación de todos los ciudadanos, de los gobiernos y la implementación de mecanismos que posibiliten alcanzar una transparencia pública.

Una vez aprobada la Ley Estatal de Archivos, los sujetos obligados, deben dar a conocer los avances del cumplimiento de la Ley en la implementación de sus subsistemas institucionales de archivo SSIAr ( estatus por dependencia y generar los proyectos y sus avances, costos y toda información relacionada) con lo que se busca, en lo general, lograr un cambio de actitud, tanto en los ciudadanos como en los sujetos obligados, y propiciar una verdadera apertura gubernamental que garantice eficazmente el derecho humano de acceso a la información pública de manera directa.Cuando el SEAr empiece a ejercer sus atribuciones, deberá al mismo tiempo transparentar los procesos archivísticos por medio de las obligaciones de transparencia.

La nueva dimensión otorgada a los archivos, responsabiliza a los sujetos obligados a cambiar su concepto de un archivo operativo a un archivo integrado a las políticas democratizadoras, como insumo de la transparencia, acceso a la información, derecho a la verdad y memoria colectiva, lo que conlleva obligaciones jurídicas, administrativas y sociales de alto nivel. Por esta dimensión es que se debe generar las condiciones desde cualquier ámbito para generar mecanismos congruentes y coordinados que permitan el eficaz cumpliiento de la Ley.

Recibido 23 de Octubre de 2019

Aceptado el 7 de Diciembre de 2019 


\section{REFERENCIAS BIBLIOGRAFICAS}

ARMIENTA HERNÁNDEZ, Gonzalo, Tratado teórico práctico de los recursos administrativos, México, Porrúa, 1991.

FÉRNANDEZ RUIZ J,ARAGÓN SALCIDO M. I., Derecho Administrativo de Sonora,México,Ed.Porrúa, 2014

GONZÁLEZ BELTRONES ADRIA VELIA, Control y Vigilancia de la Administración Pública Municipal, en BIOLEX Revista Jurídica del Departamento de Derecho UNISON URC Academia de Derecho Administrativo Tercera Época Año 7. Núm. Edición Especial Julio-Diciembre de 2015,Colección de Estudios Municipales Tomo III "Control y Vigilancia de la Administración Pública Municipal”

HARO BELCHEZ, Guillermo, Coordinador, Avances y Retos del Sistema de Control y Evaluación de la Gestión Pública y Desarrollo Administrativo en el Estado de México 1993-1999, Instituto Nacional de Administración Pública, Toluca, Estado de México1999

LANZ CÁRDENAS, José Trinidad, La contraloría y el control interno en México, México, FCE, 1987

\section{LEGISLACIÓN}

Archivo General de la Nación, Instructivo para la elaboración del Catálogo de disposición documental, Fecha de actualización: 16 de abril 2012 [en línea] Disponible en:

http://www.agn.gob.mx/menuprincipal/archivistica/pdf/instructivoCADIDO20072012 .pdf, consultado el 23 de agosto de 2019,

Decreto que aprueba el Presupuesto Anual de Egresos del Estado de Sonora. 


\section{Retos de la implementación de los Sistemas de Archivos}

Año 11, Número 21 julio-diciembre de 2019

Marcela Lorena Barraza Paredes y Adria Velia González Beltrones

Ley General de Archivos, 15 de junio de 2018, se publicó en el Diario Oficial de la Federación

Ley Orgánica del Poder Ejecutivo del Estado de Sonora

Ley del Presupuesto de Egresos, Contabilidad Gubernamental y Gasto Público Estatal,

Ley de Transparencia y Acceso a la Información del Estado de Sonora, 